\title{
Research and academic librarians: A global view
}

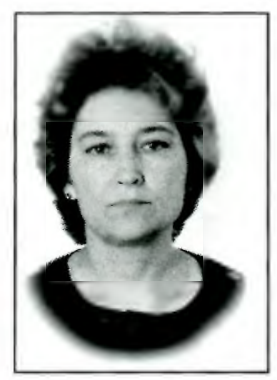

Ludmila Kozlova

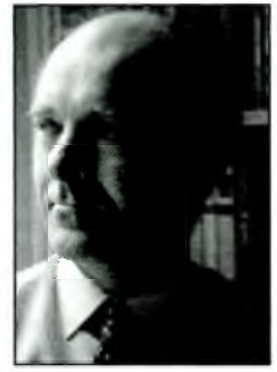

S. W. Massill

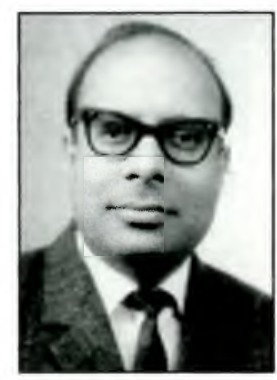

P. B. Mangla
"Research and Academic Librarians: A Global View" will be presented by ACRL's Research Committee at the ACRL National Conference at Salt Lake City, Utah. The program will be held on Tuesday, April 14 from 10:30 a.m.-12:30 p.m.

Six international speakers will discuss the role of academic library research, the rewards and impact of comparative research, and the success academic librarians have experienced in conducting their research on a continent with emphasis on their own country.

The speakers for the session will be Ludmila Kozlova, director, Department of International Library Relations, the Lenin State Library, Moscow; P. B. Mangla of the University of Delhi, India; S.W. Massill, sub librarian, University of London, England; A. L. Carvaho de Miranda, director of the Institute Brasileiro De Informacao Em Ciencia E. Tecnologia, Braslia, Brazil; James Ng'ang'a, director, Kenyatta University, Nairobi, Kenya; and Colin Taylor, chief librarian, University of South Australia, Pooraka. R. N. Sharma, director, University of
Evansville Libraries, Indiana, will moderate the program. Take advantage of this rare opportunity to hear the views of librarians from other countries and ask them questions.

"The committee is very impressed with the quality of speakers that has been proposed. We think they will do a great deal to add to the National Conference," said Charles Townley, chair, ACRL Research Committee, 1989-91.

The program has been made possible due to the contributions of Jerry Alper, Inc., Blackwell North America, Data Research, EBSCOSubscription Services, ERIC Document Reproduction Services operated by CBIS, Federal, Inc., Kenya Airways, Ohio State University Libraries, Public Affairs Information Services (PAIS), and the C. Walter and Gerda B. Mortenson Center, University of Illinois at Urbana-Champaign Libraries. The Committee would like to thank Paul Nauta, Secretary General of IFLA for helping select speakers for this special session of the ACRL Conference.--R. N. Sharma, University of Evansville, Indiana

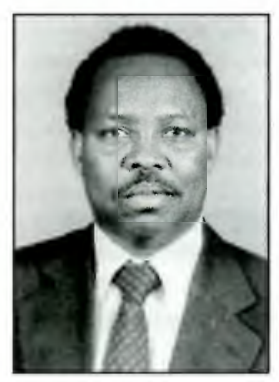

James Ng'ang'a

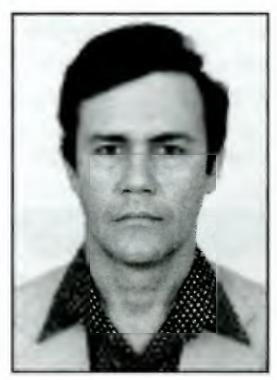

A. Carvaho de Miranda

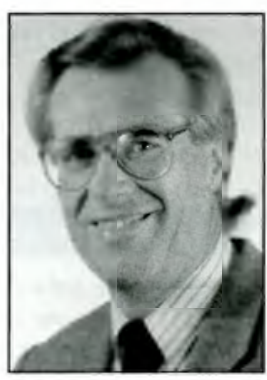

Colin Taylor 


\section{FINALY. Ethnic Mewspapers \& Magazines. FULL TEXT.}

Until now, no one had collected the significant body of newspapers and magazines published $b y$ the ethnic and minority press in America. Publications from African-Americans, Asian-Americans, Hispanics, Jewish-Americans, Native-Americans and many others. Publications representing the ethnic diversity of America. Publications with important information and perspectives-the other sides of the stories.

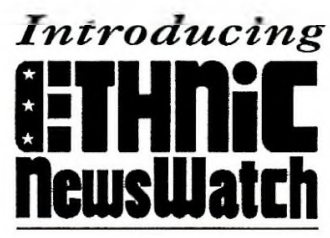

\section{A New Multicultural Database FULL TEXT on CD ROM}

\section{FliRST TIIEE EVER}

Nezespapers and magazines from the ethnic and minority press in America.

- Tho' sands of articles, edicorials and reviews - Full Text

- Every publication fully iıdexed - Fast and easy searching through one comprehensive database

- Searching across ethnic groups - Searching in English or Spanish - Spanish articles in Spanish

Ethnic Nezes Watch on CD ROM reflects the changing face of America and fills the need for information for and about a new and expanding multicultural society.

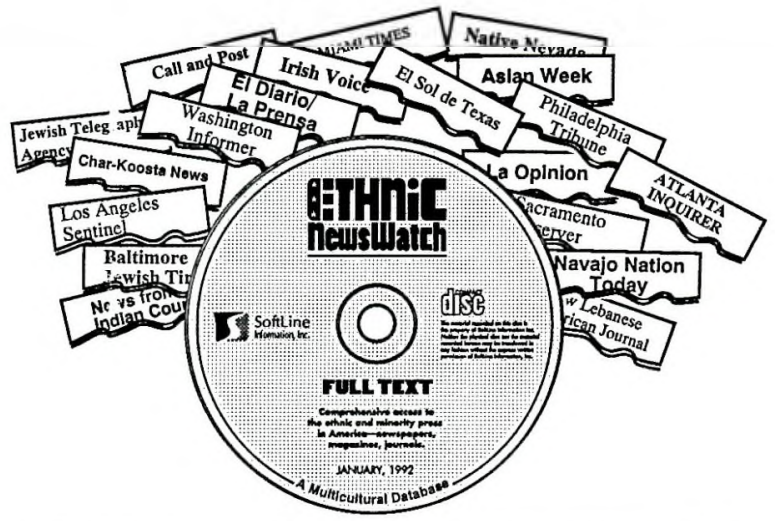

